ON INTERNATIONAL STUDENTS IN CANADA: A REVIEW OF THEIR EXPERIENCES IN THE ACADEMIC LITERATURE AND THE CANADIAN MEDIA

\author{
Submitted by \\ Sena Saidjadi \\ B.A. (Hons), York University, 2015 \\ M.A., University of Ottawa, 2017 \\ A Major Research Paper \\ Presented to Ryerson University \\ In Partial Fulfillment \\ of the Requirements for the Degree of \\ Master of Arts \\ In the Program of \\ Immigration and Settlement Studies
}

Toronto, Ontario, Canada, 2018

(C) Sena Saidjadi, 2018 


\section{Author's Declaration for Electronic Submission of a MRP}

I hereby declare that I am the sole author of this MRP. This is a true copy of the MRP, including any required final revisions.

I authorize Ryerson University to lend this MRP to other institutions or individuals for the purpose of scholarly research.

I further authorize Ryerson University to reproduce this MRP by photocopying or by other means, in total or in part, at the request of other institutions or individuals for the purpose of scholarly research.

I understand that my MRP may be made electronically available to the public.

Sena Saidjadi 


\title{
ON INTERNATIONAL STUDENTS IN CANADA: A REVIEW OF THEIR EXPERIENCES IN THE ACADEMIC LITERATURE AND THE CANADIAN MEDIA
}

\author{
(C) Sena Saidjadi, 2018 \\ Master of Arts \\ Immigration and Settlement Studies \\ Ryerson University
}

\begin{abstract}
International students are considered active, rather than passive members of the Canadian society for a wide range of factors. First, it is important to note that the arrival of these individuals equip the country's post-secondary education sector with an unprecedented amount of revenues in the form of tuition fees. Second, international students' labour work and personal spending contribute towards Canada's economic growth. Third, the presence of international students in Canada enriches the country's socio-cultural climate. Unfortunately, international students encounter several challenges during their stay in Canada and struggle to have access to a set of comprehensive settlement services to enable them to smoothly adapt into their new environment. The following study is essentially a literature review that aims to fulfill two objectives. First, there will be an examination of the experiences and struggles of these students as they have so far been reported in the academic literature and the Canadian media. Second, some of the most prevalent knowledge gaps about international students that exist in the academic literature and the Canadian media will be identified and critically analyzed.
\end{abstract}

Key Words: International Students, Language Barriers, Discrimination, Micro-Aggression, SocioCultural Challenges, Settlement Services, Knowledge Gaps. 


\section{Acknowledgements}

First and foremost, I would like to thank Allah, the Almighty for giving me strength and courage to pursue and be successful in my academic endeavors.

Second, in pursuit of this major research paper, no one has been more helpful than my supervisor, Dr. Sutama Ghosh, who devoted countless hours to read several drafts of my work and to offer me insightful feedback to enable me to improve the quality of this study. As a supervisor, Dr. Ghosh exceeded my expectations by supporting me at every single step of the way while I was producing this paper. Thank you for your endless help; I have found in you not only a mentor and a teacher, but also a best friend whom I will respect and cherish for the rest of my life.

Third, I would like to thank Dr. Mehrunnisa Ahmad Ali for accepting to be a part of this project despite her busy schedule. As a second reader, Dr. Ali provided me with valuable feedback and suggestions to help me further improve the content of this paper.

Fourth, I would like to thank my mother for always believing in me and standing by me when no one else did. Thank you for putting up with my mood swings while I was working on this research paper.

Fifth, I would like to extend my gratitude to a very special person who came into my life in early 2017 and immediately became an important part of me. Thank you for being my pillar of support, especially during my bad days. You are miles away from me, but still very close to my heart. We will probably never meet, but I want you to know that I am grateful to Allah, the Almighty, for connecting us. You will be special to me until my last breath; I will forever love you and will always regret that we could not become be a part of one another's life.

Sixth, I would like to thank two of my friends named Jiovannie and Vida for always being there for me when I needed them. In particular, I would like to thank Vida for taking the time to read my paper and offer useful grammar edits.

Finally, to all my colleagues in my cohort, I am glad to have had the occasion to meet all of you lovely people. I admire each and every one of you and wish you success in all your future endeavors. 
Table of Contents

Author's Declaration for Electronic Submission of a MRP .................................................i

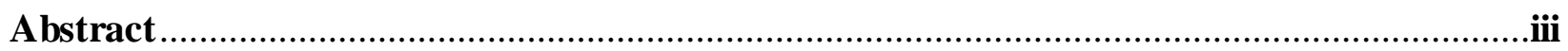

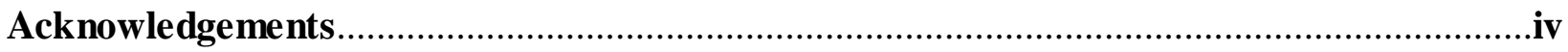

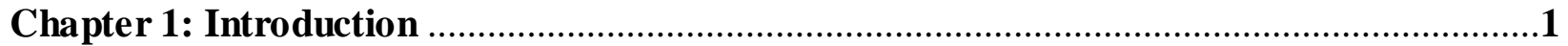

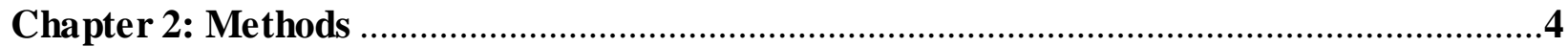

2.0. How Was the Search Conducted? ............................................................................4

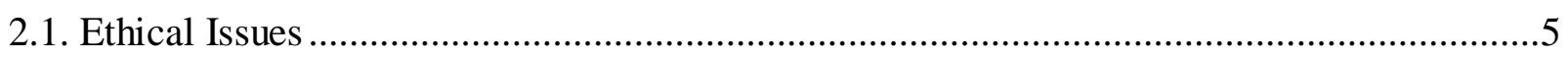

Chapter 3: Review of the Academic

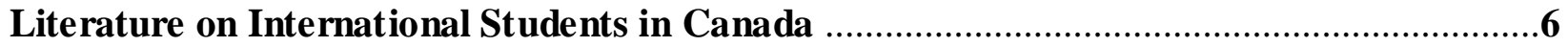

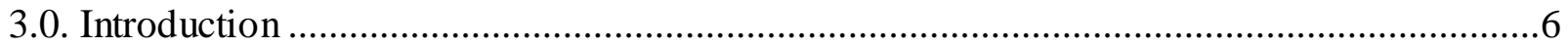

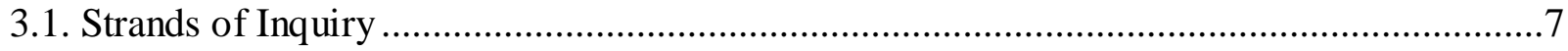

3.2. The Canadian Federal Government's

Approach to Attract International Students to Canada..................................................8

3.3. Settlement Experiences of International Students in Canadian Cities .............................11

3.4. Settlement Services for International Students ....................................................... 14

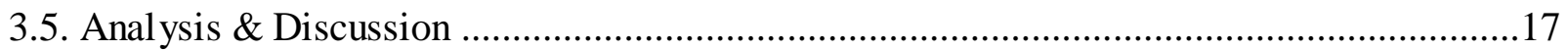

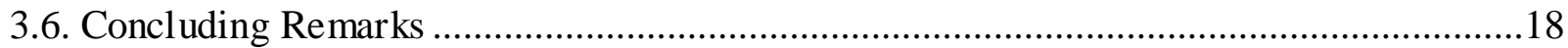

Chapter 4: Review of Canadian

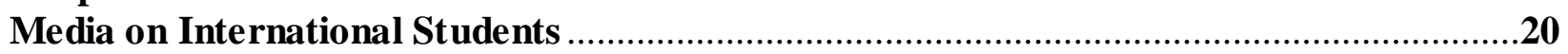

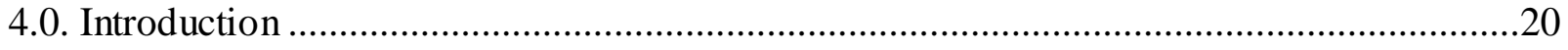

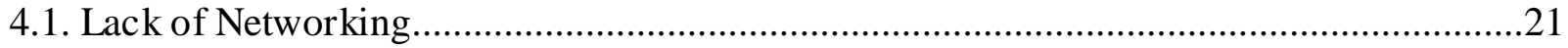

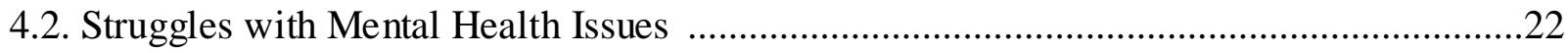

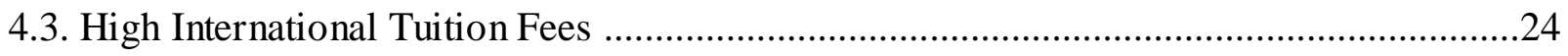

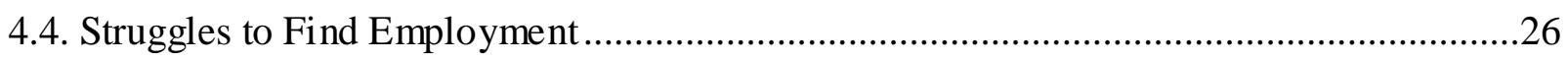

4.5. Forced Out of Canadian Schools:

The Effects of Politics on Saudi International Students ..............................................27

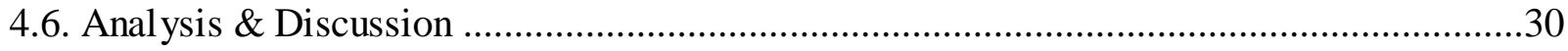

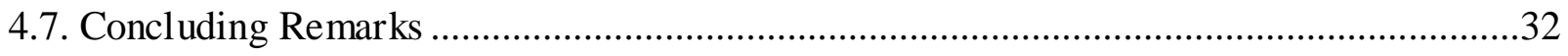

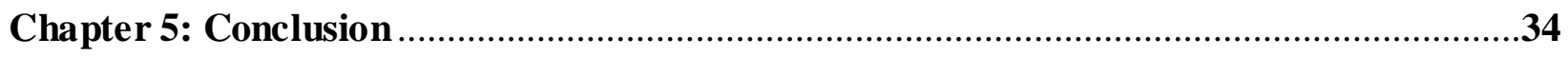

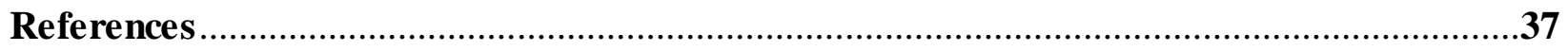




\section{CHAPTER 1}

$\underline{\text { Introduction }}$

According to the United Nations Educational, Scientific, and Cultural Organization (UNESCO), "an internationally mobile student is an individual who has physically crossed an international border between two countries with the objective to participate in educational activities in a destination country, where the destination country is different from his or her country of origin" (2015). Several statistical organizations, such as the UNESCO Institute for Statistics (UIS), the Organisation for Economic Cooperation and Development (OECD), and Project Atlas ${ }^{1}$ reveal that the total number of international students in the world has doubled within the last two decades, from 2 million in the early 2000s to 4.1 million in 2015. Although comparatively lower in volume in relation to the United States and the United Kingdom, in recent years, Canada has emerged as a significant study destination for foreign students. ${ }^{2}$ Specifically, in 2016 , there were approximately 190,000 international students in Canada (UIS, 2018).

International students represent an essential asset to the Canadian society. The arrival of these individuals equip the Canadian post-secondary education sector with an additional source of revenue in the form of high international tuition fees, as well as living costs and labour contributions (Calder et al., 2016). Apart from contributing towards Canada's economy, international students also "contribute to the diversity and internationalization of their classrooms, campuses, and communities" (Wu et al., 2015, p. 01). Simply put, the presence of these students in Canada enriches the country's socio-cultural climate through their culture, customs, traditions,

\footnotetext{
${ }^{1}$ While UIS and OECD collect data from destination countries, Project Atlas collects data from both sending and receiving countries.

${ }^{2}$ International student migration is highest to the United States, followed by the United Kingdom.
} 
and values. Thus, it can accurately be argued that international students represent active, socioculturally diverse, and economically profitable members of the Canadian society.

There are several reasons why international students choose Canada as their study destination. First, according to the 2009 National Survey of International Students in Canada, the cost of post-secondary education in Canada is more affordable in comparison to Australia, the United States, and the United Kingdom (Prairie Research Associates, 2009). In addition, unlike these other popular study destinations for international students, Canada is perceived to be a more safe and secure country (Calder et al., 2016). Furthermore, international students who come to Canada to complete their higher education are often enabled to pursue a part-time employment career without possessing a work permit. To explain the logic behind this strategy, the Minister of Public Works and Government Services Canada (2011) explains that Canada's purpose is to ensure that its foreign students can financially sustain themselves during their studies and to equip them with the required networking skills and work experience to facilitate their settlement as immigrants after their graduation.

Research has highlighted that not all international students come to Canada with the main intention of settling down as immigrants once they have graduated. Indeed, while some of these students come to this country simply in order to broaden their academic horizons, others wish to either immerse themselves in a new culture or gain valuable academic and work experience to increase job prospects on a national and international scale (Calder et al., 2016). Unfortunately, although the presence of international students in Canada is associated with a set of economic and socio-cultural advantages, these individuals are also confronted with a wide range of challenges that not only affect their academic performance, but also hinder their smooth integration to 
Canadian life. More precisely, international students in Canada struggle with several issues, which include, but are not limited to, language barriers, cultural differences, the inability to find affordable housing, the lack of belonging to a group, and mental health issues, amongst others. While some support is available to help them integrate into the Canadian society, these services are not comprehensive enough to fulfill their integration needs (Gates-Gasse, 2012).

The main objective of this study is to highlight and critically reflect upon the challenges of international students in Canada. In particular, the aim of this research is to examine the experiences of these individuals as it has so far been reported in the academic literature, as well as in the Canadian media. In the following chapter of this study, the methodology used to carry out this research will be explained. In the third chapter, the main strands of inquiry about international students in Canada in the academic literature, along with some of the most predominant knowledge gaps, will be addressed in greater depth. In the fourth chapter, the Canadian media, more specifically 'The Globe and Mail' and 'The Toronto Star' will serve as information sources to enable us to further discuss the challenges routinely encountered by international students in Canada. In this chapter, some of the most prevalent knowledge gaps about foreign students in the Canadian media, along with the recent struggles faced by Saudi international students due to the on-going diplomatic tensions between Canada and Saudi Arabia, will also be identified and critically analyzed. In the last chapter, the main ideas of this study will be summarized through a concluding synthesis. 


\section{CHAPTER 2}

\section{$\underline{\text { Methods }}$}

\subsection{How Was the Search Conducted?}

To find the appropriate material to write this literature review, a wide range of resources were consulted, including journal databases, such as the Journal of International Students, library catalogue, namely Ryerson University's online journal and article database, and newspaper databases, more precisely 'The Globe and Mail' and 'The Toronto Star'. With respect to the academic literature, specific key terms were consistently used to search for articles, such as the following: 'international students in/to Canada', 'experiences/struggles/challenges of international students in Canada', 'academic/non-academic pressures of international students in Canada', 'international students in Canada and language/cultural barriers', 'international students in Canada and micro-aggression', and so forth.

With respect to the Canadian media, a wide range of newspaper articles on the topic of international students in Canada emerged during the research stage. To avoid the study becoming too broad, the only two newspapers that were consulted are 'The Globe and Mail' and 'The Toronto Star'. There are a number of reasons which explain why these two specific newspapers were consulted. First, while the former is a national newspaper, the latter is a city-based newspaper. Considering the significant number of international students who come to Toronto to pursue their higher education, it was certainly interesting to read about the experiences of these individuals in 'The Toronto Star' and determine whether their challenges are similar or different than the ones faced by foreign students studying in other parts of Canada as they are reported in 'The Globe and Mail'. Such a comparison was necessary, given the fact that 'The Toronto Star' is a liberal newspaper targeting middle-class readership, whereas 'The Globe and Mail' tends to fall under 
the centre-right wing and has a much better and broader coverage of international matters. Another reason why 'The Globe and Mail' and 'The Toronto Star' were consulted for the purpose of this study is that during the research stage, it emerged that the number of insightful articles on international students was much greater in these two Canadian newspapers, than in others, such as the 'National Post'. Finally, it is worth mentioning that the 18 articles drawn from the selected newspapers to write this literature review discuss several common ideas about international students, hence a strong basis for comparison between the two.

Additional criteria were considered and/or followed to select the appropriate articles to be included in the research. First, these articles had to be relevant to the topic of international students in Canada. Second, with respect to the academic literature, most of the articles needed to be peerreviewed. Third, considering that the date of the selected newspaper articles is quite recent, the search for academic literature was limited to the past 10 years to ensure that all the material used to write this paper is from the same time period. This strategy enabled us to select approximately 20 peer-reviewed articles out of an estimated 40-50 scholarly articles.

\subsection{Ethical Issues}

This literature review was written without involving any human participant. Despite this fact, some ethical issues that one would encounter while working on this type of project ought to be mentioned. Whether one is conducting primary research or simply writing a literature review, one must honestly report their findings. In the case of this study, the research findings have not been made up; rather, they have all been accurately reported and all the references have been acknowledged throughout the paper. In fact, to ensure that everything reported in this study is credible and to respect the intellectual property rights of all the authors cited in this paper, this work has been rigorously reviewed. 


\title{
CHAPTER 3
}

\author{
Review of the Academic \\ Literature on International Students in Canada
}

\subsection{Introduction}

International students form an integral part of the Canadian population. They belong to different countries and speak a variety of different languages (Rae Cox, 2014). Over the years, the landscape of Canadian post-secondary institutions has become increasingly "multicultural as its major cities" (Rae Cox, 2014, p. 01). Although the existing academic literature properly excels at addressing the challenges and struggles encountered by these individuals both on- and off-campus, it also contains some knowledge gaps which will be discussed later in this chapter. First, it is critical to note that in 1950, a national organization commonly known by the name of 'Friendly Relations with Overseas Students' was established in the city of Toronto. It recognized the importance of foreign students in a post-war Canadian society and the pressing need to offer them support and settlement services to enable them to successfully integrate in their chosen institution (Cameron, 2006).

While this organization was being founded, international students in Canada steadily became one of the main objects of discussion in academia. Indeed, towards the end of the 1950s and the beginning of the 1960s, a significant quantity of academic literature addressing the origins and to some extent - experiences of these students emerged (Cameron, 2006). Since international students in Canada have traditionally been viewed as temporary migrants, rather than immigrants, they have been overlooked in the historical literature on Canadian immigration (Cameron, 2006). In the early 1970s, an unprecedented number of international students from India and China came to Canada to pursue a higher education in the STEM fields, which comprise of Science, Technology, Engineering, and Mathematics. Interestingly, Cameron (2006) states that "almost all 
of the published research about [international students], extending from the early 1970s to now is devoted to contemporary trends and developments, and not to historical study" (p. 03).

This chapter aims to fulfill the following objectives. First, the main strands of inquiry about international students in Canada in the academic literature will be identified. Second, the Canadian federal government's approach to attract international students will be discussed. Third, the major struggles encountered by international students, mainly on-campus, will be critically scrutinized. Fourth, some of the most prevalent knowledge gaps that exist in the existing academic literature on international students in Canada will be highlighted and analyzed. Finally, some concluding remarks will be offered to summarize the main ideas of this chapter.

\subsection{Strands of Inquiry}

A review of the Canadian academic literature on international students in Canada reveals that most studies in Canada have focussed on graduate student experiences in Canadian institutions. Disregarding this important knowledge gap, the following is a list of the main strands of inquiry about international students in Canada in the existing academic literature:

1. The federal government's approach to attract international students to Canada;

2. Settlement experiences of international students in Canadian cities;

3. Settlement services available for the successful integration of international students to Canada.

In the next few sections of this chapter, each one of these strands of inquiry will be explained and analyzed in greater depth. 


\subsection{The Canadian Federal Government's}

Approach to Attract International Students to Canada

Immigration to Canada is a federal responsibility. It was mentioned earlier that international students represent a precious human capital for the Canadian economy (Hawthorne, 2012). However, as evident from statistical records, this category of temporary migrants was not always the favoured immigrant class. ${ }^{3}$ As shown in the chart below, there has been a sudden rise in the volume of migration under this category since 2006. In that year, about 68,000 international students came to Canada, whereas in the very next year, i.e., 2007, close to 100,000 had arrived (UIS). Thus, it may be argued that this sudden rise in the number of international students to Canada is intricately tied with the federal government's response to skilled-worker migration.

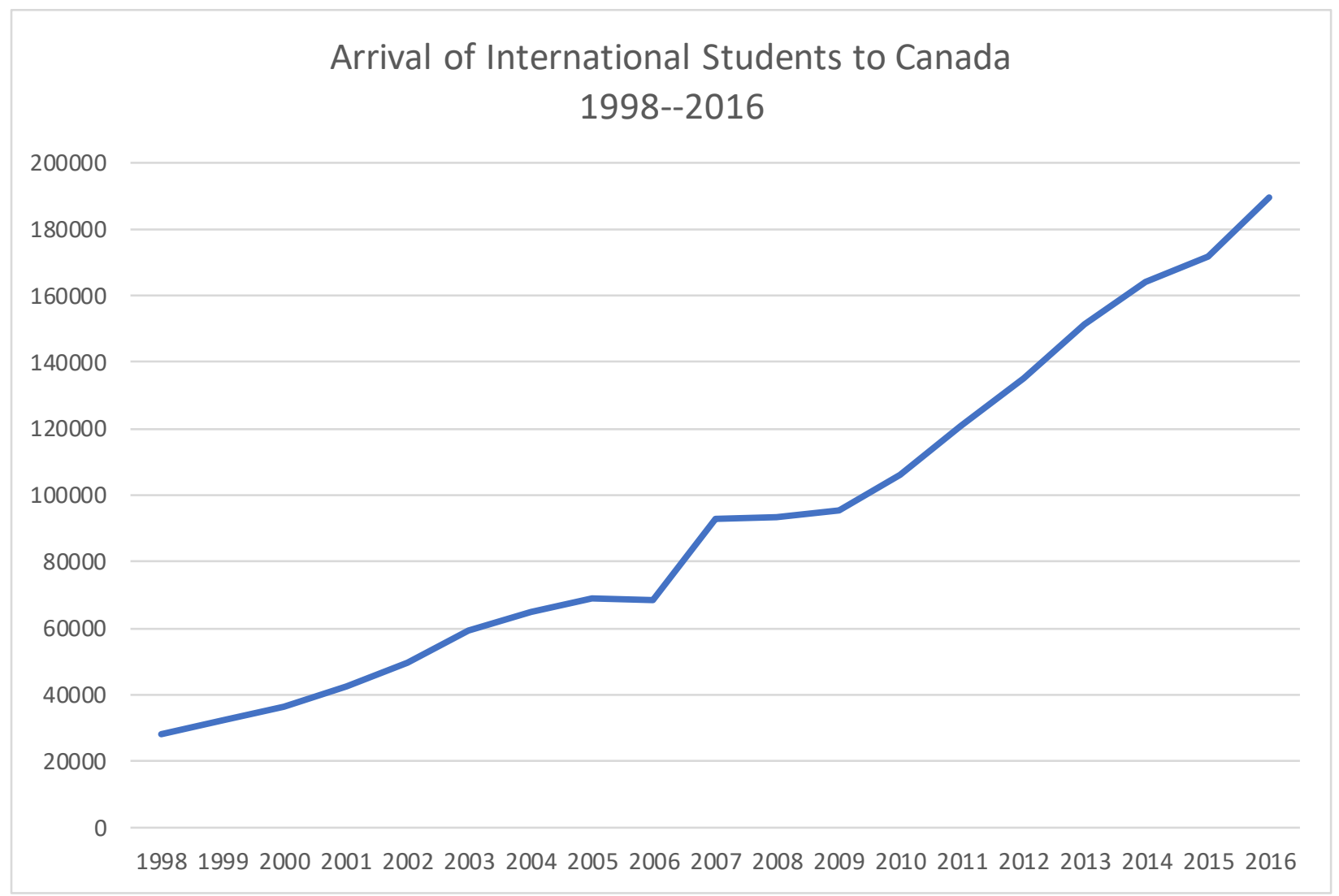

${ }^{3}$ For instance, in 1998, Canada had only 28,000 inbound international students. 
Since the amendment of the 1976 Immigration Act, many highly-skilled migrants have settled in Canada. ${ }^{4}$ Over the last three decades, several studies have reported that the labour market outcomes of skilled immigrants in general and recent immigrants more particularly are unsatisfactory. Unlike their Canadian-born counterparts, the earnings of 'recent' immigrant men and women are much lower (Roach, 2011). In this light, some studies found that "schooling gained in Canada [is strongly] correlated with higher rates of return to post-secondary education for immigrants" (Roach, 2011, p. 09). The rationale being that individuals who already possess Canadian educational qualifications are less likely to struggle to obtain professional credentials or adapt to a new culture or language. Presumably, they are also less likely to be affected by the earning gaps that exist between immigrants and their Canadian-born counterparts. In sum, international students will not only contribute to the economy, they will also supposedly require little to no support at all from the state for their survival (Roach, 2011). Although the first claim is accurate, the second one is not, and this will be discussed in detail later in this chapter.

To address its commitment to a high skill economy, the federal government uses a threepronged approach to attract foreign students: (1) provide financial incentives to these students, i.e., scholarships, (2) brand campaigns to improve the quality and values of education for international students, regardless of their level or area of study, and (3) introduce new immigration programs

\footnotetext{
${ }^{4}$ Since the early 1990s, Canada's social politics have been strongly influenced by a "shift towards a neoliberal agenda [which] became particularly evident in Canadian Immigration policy" (Roach, 2011, p. 04). According to Arat-Koç (2009) (as also cited in Roach, 2011), it was during this period when the 1976 Immigration Act was amended by the Progressive Conservative government to attract capital-rich and market-friendly immigrants to benefit Canada's economy and strengthen the country's global competitive advantage (Roach, 2011). One of the targeted groups of immigrants were "business and professional immigrants with substantial amounts of human and monetary capital" (Roach, 2011,p. 04). Apart from these individuals, the Canadian federal government sought to encourage temporary foreign workers to come to Canada as well, so that their presence could "fill the short-term labour market demands" (Roach, 2011, pp. 04-05). Thus, with the amended act, immigration applications were no longer solely assessed on the points-system, but as well as on labour market flexibility (Roach, 2011).
} 
(She and Wotherspoon, 2013). Toward this goal, in the past two decades, the Canadian government has "launched a series of policy initiatives to expedite the processing of study permit applications" (She and Wotherspoon, 2013, p. 03) and enable international students to access the Canadian labour market not only during their studies, but as well as after their graduation. These policy initiatives include "the national roll-out for the Off-Campus Work Permit Program [...], the extension of the validity of Post-Graduation Work Permit to up to three years $[\ldots]$, and the implementation of the Canadian Experience Class" (She and Wotherspoon, 2013, p. 03).

It was earlier mentioned that in the context of labour market shortages, international students are portrayed as 'ideal' immigrants for two reasons. First, it has been argued that the presence and labour contributions of these individuals will be profitable for the economic market. Second, these students supposedly require little to no support at all from the state for their survival (Roach, 2011). Although the first claim is accurate, the second one is not, given that international students in Canada require different types of assistance during the various stages of their stay. First, during their study period, they require support from their peers and faculty members to develop their sense of belonging to their academic institution. Second, while they are studying, international students require off-campus assistance from settlement agencies to be able to find affordable housing, manage their expenses, and so forth. Finally, during their post-study period, these individuals often require help from employment agencies to help them connect with employers in their chosen field (Calder et al., 2016). Having said that, literature that specifically focuses on the settlement experiences of international students in Canadian cities will be discussed in the next section. 


\subsection{Settlement Experiences of International Students in Canadian Cities}

The extant literature recognises two significant barriers faced by international students in Canada which significantly impact their access to housing, employment, and full participation in the Canadian society. These two challenges are language barriers and discrimination and microaggression. It is important to note here that the majority of the Canadian literature focuses on the settlement experiences of Chinese and Indian students in Canada. This is understandable, given that China and India are among the top five source countries for foreign students in Canada (Statistics Canada, 2016).

If one critically reflects upon the existing academic literature, then one realizes that within the realm of education, social inclusivity is a far-fetched ideal. Indeed, numerous studies conducted in the past decade describe in detail the struggles of international students in Canada, especially on-campus. Indeed, in their study, Wu et al. $(2015)^{5}$ have thoroughly reported the struggles of Liu, a Chinese international student attending a Canadian post-secondary institution. These scholars have explicitly highlighted that due to her lack of English proficiency and her inability to adapt to new pedagogical methods and study patterns, Liu has become academically dislocated. In simpler terms, she often struggles to understand her instructors, which in turn makes it even more difficult for her to follow their lectures with ease. As a result, she fails to actively participate in the classroom. Although she always feels isolated from the rest of the classroom, she still pretends to understand everything as she does not want her instructors to have a negative impression about her. Contrary to Chinese international students, Indian students have a better command of the

\footnotetext{
${ }^{5}$ Although this study primarily focuses on a selected number of participants attending a public college in the United States, a section of the literature review extensively highlights the consequences of language barriers for international students in Canada.
} 
English language, which makes it easier for them to connect with their Canadian-born classmates. Surprisingly, however, most of them prefer to hang out with their fellow Indian classmates instead of domestic Canadian students (Zhou and Zhang, 2014). Thus, in the case of these Indian students, it is quite evident that their sense of belonging to the domestic members of their new environment is not as strong as their sense of belonging to their circle of Indian friends.

In Zhou's and Zhang's (2014) study, the academic and non-academic challenges frequently encountered by international students from different nationalities, i.e., India, China, Turkey, etc., are well described. With respect to the Indian participants, they primarily reported their struggles in trying to balance their socio-academic life and personal living. Specifically, one of them stated that they find it "hard to sit down and study along with cooking, along with meeting friends, and tying to socialize" (Zhou and Zhang, 2014, p. 08). Another Indian participant reported the struggles they faced during their initial days in Canada in trying to adapt to new pedagogical methods and study patterns. To further shed light on their academic experiences, the participant revealed that upon their arrival in Canada, they quickly became overwhelmed with the amount of work they needed to complete for their courses on a weekly basis. The participant further explained that contrary to their home country, India, where students only study during the exam period, students in Canada are expected to continuously study throughout the semester (Zhou and Zhang, 2014).

Apart from language barriers, international students are normally subjected to an exclusive learning environment in which they suffer from various forms of discrimination and microaggression, including racial invalidation and insults (Houshmand et al., 2014). In their study, Houshmand et al. (2014) conducted short unstructured interviews with a selected number of Chinese students attending a Canadian university whose name is not specified. The participants 
unanimously complained about their exclusion from campus life. Specifically, they explained how they are often assaulted and insulted by their own peers. Approximately $50 \%$ of the participants even reported that they are usually ridiculed in the classroom for their accent. An important theme that emerged in Houshmand et al.'s study (2014) is that of invisibility. Indeed, most of the Chinese participants openly shared their concern about their presence on-campus not being visible or wanted, let alone acknowledged. Some of the participants also explained that their feelings of invisibility have become stronger over time due to the fact that the local people prefer to disregard international values and needs for the sake of their own culture and way of living.

It has been recognized both in Canadian studies and studies conducted in the United States that international students are often ridiculed for their accent and lack of understanding certain concepts. ${ }^{6}$ While the participants in Houshmand et al.'s (2014) study reported that they are solely ridiculed by their peers, the South African participants in Naidoo's (2012) study claimed that aside from their peers, their instructors also ridicule them, especially in the classroom. As a result of these barriers, unfortunately, upon their arrival in Canada, most of these students are exposed to an unprecedented culture shock, which makes it difficult for them to understand and adapt to Canadian lifestyle (Wu et al., 2015). Specifically, these students struggle to connect with their faculty members and peers, let alone effectively communicate with them. Thus, they begin nourishing feelings of inferiority, isolation, and loneliness. With the progression of time, many of them end up suffering from anxiety, acculturative stress, and depression (Wu et al., 2015). To

\footnotetext{
${ }^{6}$ For instance, David Naidoo's (2012) study, which was conducted and published two years earlier than Houshmand et al.'s (2014) article, focuses on international students attending a South African post-secondary institution. Interestingly, some of the results reported by Naidoo (2012) strongly correlate with those highlighted by Houshmand et al. (2014).
} 
avoid these issues, it is crucial that international students receive a sense of emotional support from the members of their new environment.

Finally, according to Poteet and Gomez (2015), intersectionality is an extremely important concept that ought to be considered to enable us to understand how "a precarious status $[\ldots]$ interact[s] with race, culture, language, gender, and social class for international students in specific contexts of reception" (p. 89). In their study, Poteet and Gomez (2015) opted for an intersectional, multicultural, and integration lens that allowed them to comprehend that international students in Canada are often exposed to various forms of racial discrimination, including covert racism and overt racism. Interestingly, the participants reported that they did not simply see themselves as victims of racism in their interactions with Canadians, but as well as "active agents in an ongoing and dynamic multicultural context that was open to change" (Poteet \& Gomez, 2015, p. 97). Thus, Poteet's and Gomez's (2015) statement implies that these students are themselves partly responsible for their state of loneliness which is a result of "their lack of integration with Canadian students" (p. 95).

\subsection{Settlement Services for International Students}

International students in Canada require a wide range of settlement and support services to connect with their new surroundings and form new friendships. Within the realm of education, settlement services play a pivotal role to enable international students to connect with their peers on-campus and effectively communicate with their faculty members. In her study, Roach (2011) argues that the Canadian federal government has introduced numerous immigration policy reforms with the main intention of attracting and retaining highly qualified international students. However, she also mentions that these immigration policy reforms "have not been accompanied 
by the necessary changes to traditional settlement and international student services"(2011,p. 01). Gates-Gates (2012) also agrees that international students in Canada often struggle to have access to "comprehensive settlement services and supports $[\ldots]$ to facilitate [their] smooth transition towards their full integration and participation in [the] Canadian society" (p. 272). Calder et al. (2016) further explain that these individuals require social support, which comprises of both financial and emotional support, from their faculty members and peers. This is particularly integral for their mental well-being, as well as to enable them to make the most out of their experience as international students.

Some Canadian studies have highlighted that due to certain governmental policies, international students are often restricted to have access to numerous settlement services that are funded by the different pillars of the Canadian government (Rae Cox, 2014; Gates-Gasse, 2012). To further explain this idea, Rae Cox (2014) mentions that international students are normally portrayed as temporary migrants in the public discourse and, as such, they are excluded from a set of rights and services that are usually bestowed upon individuals with a formal residency status, such as immigrants and/or refugees. Although there are a number of service gaps, Calder et al. (2016) explicitly mention that most institutions across Canada offer settlement and support services to their international students; however, the issue is that the latter are unaware of them and prefer to seek help from their personal networks, which include their family members, friends, and former and present faculty colleagues. Thus, as claimed by Calder et al. (2016) and Poteet and Gomez (2015), international students must assume their own share of responsibilities to receive the help that they require. 
In her study, Rae Cox (2014) describes the pathway approach as a creative and useful medium to provide settlement services to international students. The basis of the pathway approach is Dr. Abu Kamara's and Dr. Liesl L. Gambold's 2011 pilot study focusing on the needs and settlement challenges of international students. The pathway approach is comprised of three distinct phases. Rae Cox (2014) informs that the first phase requires necessary tools to be provided to international students, either during the pre-departure orientation program organized by Citizenship and Immigration Canada (CIC) or during peer mentoring/orientation programs organized by their chosen institution. The aim behind this strategy is to enable students to become familiar with pre-arrival settlement services and with their program of study's academic requirements. As for the second phase of the pathway approach, Rae Cox (2014) mentions that its purpose is to encourage international students to complete a self-assessment report and submit it to their school. The institution must then assess the strengths and needs of their international students and foster appropriate academic and settlement services to help them build their selfconfidence, succeed in their studies, and contribute to school life. Finally, Rae Cox (2014) highlights that the aim of the third phase of the pathway approach is to provide faculty and staff with "socio-cultural training to support increasingly diverse international student populations" (p. 67). Specifically, the aim of the third phase is to propel all teaching and administrative members of any given post-secondary institution to do the following: (1) inspect the causes and consequences of common challenges encountered by international students; (2) determine whether the existing academic and settlement services are helpful to these students; (3) devote time and invest additional efforts to put forth new measures to enable these students to combat their barriers to success and integration in the Canadian society (Rae Cox, 2014). 


\subsection{Analysis \& Discussion}

First and foremost, it needs to be recognized that the geographical context matters at the inter- and intra-urban scales. On a global scale, it is recognized that the experiences of and challenges encountered by international students in one country may strongly differ from those faced by foreign students attending school elsewhere. Therefore, there is a strong need for comparative studies on the experiences of international students in different countries. However, it is important to also realize that the experiences of international students differ between and within Canadian cities. In addition, the experiences of these students differ by the type of institutions they attend. For example, the experiences of an international student in Toronto, Ontario are most likely different than those of a foreign student in Edmonton, Alberta. Similarly, within Toronto, the experiences of international students, whether they are attending university or college, may also differ.

Secondly, more research needs to be conducted in order to thoroughly investigate the struggles of international students both on- and off-campus. This type of research will be particularly useful to enable both the researcher and the reader to determine whether the challenges encountered by these individuals on-campus differ from the ones they face off-campus. If so, then this type of research would turn out to be a stepping stone for researchers to conduct and publish additional research to identify concrete strategies to help international students to simultaneously overcome their on-campus and off-campus struggles.

Thirdly, most of the existing academic literature focus on graduate and post-graduate international students; the number of resources that explore the experiences of undergraduate international students in Canada is limited. Fourthly, although the experiences of international 
students from East-Asian or South Asian background, such as Chinese and Indian students have been well documented, there is relatively very few scholarly articles available on international students from other nationalities, such as Saudi Arabia or Africa. Thus, there is a pressing need for additional research to be conducted to enable us to determine how similar and different are the experiences and the pathway to full integration of international students from diverse backgrounds.

Fifthly, it is critical to note that there are relatively few academic studies that explore the issue of belonging for international students through an intersectional lens. Previously in this chapter, Poteet's and Gomez's (2015) study was introduced to shed light on the fact that as active agents, international students ought to involve themselves in social activities to be able connect with members of their host society and, in doing so, broaden their understanding of services that are available to them. It should be noted that the focus of this study is on international students in Atlantic Canada; if a similar study is ever conducted on international students living and studying in other parts of Canada, such as Ontario, that would be an original contribution to knowledge. Indeed, using an intersectional lens, it would be helpful to critically explore the experiences of international students attending either an Ontario university or college through their interaction with other members of their community who are different than them in terms of race, gender, age, and sex.

\subsection{Concluding Remarks}

As mentioned throughout this chapter, international students in Canada are confronted with several challenges that affect their well-being and academic performance. Most of their struggles are thoroughly discussed in the existing academic literature. This chapter highlighted that international students in Canada struggle to find affordable housing, connect with their peers and 
faculty members, integrate themselves and actively participate in the Canadian society, and so forth. In addition, several academic studies have highlighted some possible strategies and solutions to enable these students to combat their barriers to success, such as peer mentorship programs. This chapter further elucidated that while some support is available to these students both on- and off-campus, these individuals are not always aware of them. In the coming years, additional settlement services ought to be fostered by both the post-secondary institutions and the Canadian government to enable these individuals to confront their struggles, rather than succumbing to them. Finally, a critical issue that was raised in this chapter is that the existing academic literature has a number of knowledge gaps that must be addressed to allow us to compare the experiences and struggles of international students in Canada both on a macro- and micro-level. 


\section{CHAPTER 4}

Review of Canadian

Media on International Students

\subsection{Introduction}

The previous chapter focused on a selected number of academic literatures to examine the origin, history, experiences, and struggles of international students in Canada. As discussed, the plight of these individuals has been depicted quite well in most of these studies published in the past decade, though some knowledge gaps remain. To supplement our review and discussion of the academic literature on international students in Canada, this chapter proposes to critically look at some Canadian newspaper articles on the same topic. The logic behind this proposal is that in academia, issues are often discussed from a critically subjective point of view, whereas media, whose actions are regulated by influential authorities, usually delivers biased and/or misleading news to the public. Thus, the aim of this chapter is to determine whether the experiences and struggles of international students in Canada are portrayed differently than or in the exact same way as the academic literature. The ultimate purpose of this chapter is to highlight themes and facts about international students in Canada as they are discussed in both the academic literature and the Canadian media.

In the selected newspaper articles, the debate on international students in Canada is grounded on several themes. First, international students' academic and non-academic struggles are one of the main topics of discussion. Specifically, their inability to build new networks and adapt to new study patterns are well explained in these articles. Second, international students' struggles with mental health issues is another crucial topic of discussion. Third, the issue of high tuition fees that international students must pay is another critical theme reported and thoroughly analyzed in some 
of these articles. Finally, the obstacles that most foreign students encounter while they are trying to find employment in their field after their graduation are also well described.

In this chapter, the following objectives will be fulfilled. First, a more concrete explanation and analysis will be offered regarding each one of the previously-mentioned strands of inquiry. Second, a detailed description of the recent struggles encountered by Saudi international students in Canada will be provided. Third, a discussion will be put forth to identify some of the knowledge gaps about international students in Canada in the selected newspaper articles. Finally, the chapter will end with some concluding remarks. It is critical to mention that throughout the next paragraphs, some comparison will also be made to highlight ideas and facts about international students that are commonly discussed both in the academic literature and the Canadian media.

\subsection{Lack of Networking}

As mentioned in the previous chapter, international students often struggle to adapt to life in Canada, connect and effectively communicate with their faculty members, and make new friends. This reality is well depicted in the Canadian media as well. Indeed, Bradshaw (2018) posits that a significant portion of undergraduate and graduate international students usually reporthaving very few friends. With respect to international students from Africa and Asia, it has been shown that they often find it difficult to network with people from different walks of life, sexualities, races, and perspectives (Habib, 2017b). In the case of these students, Habib (2017b) specifically asserts that being new to Canada, they often struggle to find their way around the campus, as well as offcampus. In addition, most of these students reported feeling overwhelmed by academic stress and confronting difficulties navigating the online course platform, selecting the appropriate courses, and applying for financial aid (Habib, 2017b). 
To avoid becoming anti-social, these students ought to associate themselves with their classmates; however, this is not always easy to do, especially if one has newly arrived in a country that one has never visited before and if one does not have any contacts with anyone. In fact, international students are not always welcomed with open arms by their peers. To prove this claim, Keung (2015) recounts the story of a male undergraduate international student from Taiwan. He mentions that the student was often ridiculed by his peers for his accent; this fact has also been examined in the previous chapter. Keung (2015) further states that because of the way he was treated by his peers, the student was discouraged to speak in public or make friends. As a result, he became overly anti-social. Due to their inability to build networks, international students, especially undergraduate students, suffer from a wide range of mental health issues which will be investigated in greater depth in the next section.

\subsection{Struggles with Mental Health Issues}

In his article, McDonald (2017) advances that a significant portion of international students studying in Canada often experience severe mental health issues, including depression, anxiety, and bipolar disorder. To underline the severity of these issues, some of them even commit suicide when they fail to cope with their daily stress. According to Attfield (2017), the rate of suicide of international students is increasing at a fast rate. This is mainly due to the fact that these students are often unable to receive the support that they require, such assistance in forging relationships with their classmates from different nationalities through peer mentorship programs; the latter has been identified by many academics to be one of the most effective strategies to enable foreign students to develop their sense of belonging to their new society. 
Let us consider two scenarios to better assess international students' struggles with mental health issues. First, McDonald (2017) provides the example of a student named Anderson who expressed that, after a positive first year, he alarmingly started losing weight. This was mainly due to his struggle with isolation that eventually led him to suffer from anxiety and depression. On the advice of his physician, he eventually decided to take a year off from school. Second, Pang's (2017) article addresses the difficulties that international students encounter as they seek help to combat their mental health issues. Pang (2017) puts forth the example of a student named Audrey Carleton who is suffering from ADHD due to her experience as an international student. Pang (2017) explains that due to some miscommunication with the university's psychiatrist, Carleton has been taken off her medications. In addition, because of her status as an international student, Carleton is unable to get same-day appointments. As a result, this caused her to experience "feelings of low self-esteem or self-loathing" (Pang, 2017, par. 09).

Due to the lack of inclusion and respect for international students in the host society, these individuals are forced to significantly suffer from mental health issues. However, it is critical to elucidate that the effects of these conditions are further escalated when these students do not have any type of emotional support, whether it be from family or friends. To better illustrate this scenario, Ngabo (2018) recounts the story of an undergraduate international student from Rwanda whose first four months of stay in Canada was a pure traumatic experience. Indeed, Ngabo (2018) explains that the subject suffered from severe loneliness and depression during this period; the student was also un-appealed by Canadian food and could not cope with the weather. As a result, his condition worsened. Attfield (2017) explains that the first few months of a freshman school year, despite being exciting, represent a critical period during which international students determine whether they are to thrive or not. Thus, it can be concluded that if the student from 
Rwanda had been able to make friends or if he had a family member close-by, they could have helped him to come out of his shell, combat his illness, and thrive.

\subsection{High International Tuition Fees}

Apart from their lack of networking and struggles with mental health issues, Chakma (2010) and Brown (2014) posit that international students in Canada are persistently confronted with incredibly high tuition fees. Chakma (2010) also explains that these individuals struggle to have access to an affordable health care plan. Brown (2014) further sheds light on this reality by mentioning that due to the unrecognizable status of their student health coverage, international students are often required to pay for primary health care services from their own pocket. Given the financial obligations that they must fulfill to be able to complete their studies effectively and on time, international students ought to manage their money wisely. Unfortunately, despite wanting to properly manage their financial resources, international students are sometimes confronted with unforeseen circumstances that lead them to incur unnecessary expenses.

Indeed, Loriggio (2017) highlights that international students are sometimes forced to pay for unnecessary things, such as additional tuition fees, due to the tensions that take place in the host society, more precisely between the institution that they are attending and the trade union. To prove her claim, Loriggio (2017) recounts the story of Noble Thomas, an international student from India pursuing a degree in Human Resources (HR) at Confederation College, located in Thunder Bay, Ontario. She asserts that due to faculty strike, Thomas ended up incurring additional expenses and his graduation was delayed. Moreover, Loriggio (2017) elucidates that due to faculty strikes, international students often experience issues with their visa and study permit, which are granted to them on the condition that they shall make continual progress towards the completion 
of their study program. It should be noted that international students often struggle to acquire their study permit to be able to study abroad. Unfortunately, due to these strikes, these students are unable to meet this condition and, as such, their chances of getting deported increase. Thus, they are left with the following two options: (1) continue paying additional fees to remain registered in their program of study, or (2) withdraw from it and request a refund, hence jeopardizing their study permit, as well as their plans of settling down in Canada as permanent residents following their graduation.

Within this framework of discussion, it is critical to mention that international students' request for a refund, especially at a time when the school is either on strike or shuts down, is not always approved by the financial bureau of their institution. To shed light on this unfortunate reality, Fiorito (2008) provides the example of Allen, a male undergraduate international student from Taiwan. Allen's mission for coming to Canada was to learn English and then attend a Canadian university to complete an undergraduate degree. To fulfill his dream, "he used his own savings to pay for his trip and his courses" (Fiorito, 2008, par. 07). Allen paid an incredibly high amount of tuition fees to Pattison College, the Toronto-based English Second Language (ESL) education center in which he had enrolled. Shortly thereafter, the education center shut down. Surprisingly, however, Allen did not receive any refund, nor did he have any type of academic or legal support during his stay in Canada. Fiorito (2008) further mentions that Allen extended his visa and continued living in Canada under a very tight financial situation, so that he could receive his refund; however, that did not happen even after a year had passed since Pattison College's permanent closure. 


\subsection{Struggles to Find Employment}

The fact that international students must pay exceptionally high tuition fees to acquire Canadian educational qualifications is a pressing concern for these individuals who often take a loan to pursue their academic endeavours. Despites having to endure financial hassles to fulfill their dream of acquiring a Canadian education, international students struggle to find a job in their field once they graduate. Indeed, Habib (2017a) asserts that once international students gain the required skills and knowledge through their Canadian education, getting jobs in the fields that correspond with their major is often problematic. To prove her claim, Habib (2017a) gives the example of Dr. Kabir, originally from Bangladesh, who ended up driving for Uber, even though he holds a $\mathrm{PhD}$ in Anthropology from a Canadian university. Another example provided by Habib (2017a) is that of Dr. Shokry who was forced to work in a call centre despite pursuing a medical degree in Canada. Similarly, Yalnizyan and Grisdale (2016) recount the story of Lucas, a foreign student from Brazil to highlight that despite having paid a whopping $\$ 15,000$ on an annual basis in tuition fees to secure a Canadian degree, he ended up returning to Brazil and was uncertain whether he would be able to secure a job for himself there.

As one can notice, the Canadian media has engaged in an appropriate measure in discussing the academic and non-academic struggles faced by international students. More specifically, the selected articles from 'The Globe and Mail' and 'The Toronto Star' produce stories and commentaries that adequately emphasize the importance of addressing these challenges to enable these individuals to adapt to life in Canada, concentrate on their studies, and have a successful overall experience. Additionally, it is important to highlight that the Canadian media often puts forth scenarios to shed light on the struggles of international students in Canada. These examples are very much appreciated; however, these specific instances cannot and must not be used for 
generalization or over-generalization purposes. Indeed, if one student or a particular group of international students is struggling either to pay for their tuition fees or with mental health issues, that does not imply that every single foreign student in Canada is confronted with the same struggles. Thus, it can be argued that the media often blows critical issues out of proportion.

As was the case with the academic literature, the selected newspaper articles have few knowledge gaps that ought to be addressed to allow us to identify themes and facts about international students in Canada that have not yet been discussed in the Canadian media. This will also enable us to determine whether there are any common knowledge gaps about these subjects in both the academic literature and the Canadian media. Prior to scrutinizing these knowledge gaps, it would be interesting to discuss some of the effects of politics on international students. Thus, the following section of this study will meticulously review the case of Saudi international students in Canada who have recently been ordered to withdraw from their program of study and return to Saudi Arabia. It would be highly interesting to determine whether the Canadian media has portrayed the challenges of these students in a fair or biased/disproportional manner.

\subsection{Forced Out of Canadian Schools:}

The Effects of Politics on Saudi International Students

Canada is an ardent defender of human rights, "including women's rights and freedom of expression around the world" (Donovan, 2018, par. 23). In early August 2018, Chrystia Freeland, Canada's Foreign Affairs Minister, along with her department, made a statement on Twitter to condemn Saudi Arabia's decision for detaining civil-rights activists (Remiorz, 2018). Canadian officials demanded the Saudi government to immediately release several women's rights activists, such as Samar Badawi, who are currently detained in the Islamic Kingdom. Interestingly, back in 2012, Samar's brother made some critical comments about Islam in his blog that were not well- 
received by Saudi Arabia. As a result, Raif was arrested, tortured, and sentenced up to 10 years in prison (Donovan, 2018). Upon learning about Samar's recent imprisonment in Saudi Arabia, the Canadian government decided to stand up for her rights, as well as the rights of other women's activists. The Canadian government publicly criticized Saudi Arabia's human rights record (Remiorz, 2018) and ordered the Islamic Kingdom to be more compassionate towards these activists and release them (Donovan, 2018). The Saudi Arabian government labelled Canada's comments as "blatant interference in its domestic affairs" (Remiorz, 2018, par. 03). In fact, in retaliation to Canada's comments and demands, Saudi Arabia opted for two punitive meas ures. First, Dennis Horak, Canada's ambassador to Saudi Arabia, was ordered to leave the country within 24 hours (Donovan, 2018). Second, the Islamic Kingdom suspended scholarships for close to 16,000 Saudi students studying in Canada and ordered them to immediately leave the country and pursue their education from elsewhere (Donovan, 2018; Remiorz, 2018).

According to Momani (as cited in Donovan, 2018), who is a Professor of Political Science at the University of Waterloo and an expert on Middle Eastern issues, Saudi Arabia's retaliation is in reality geared towards making an "example out of Canada by showing the world [that it does not and will not] take comments critical of domestic Saudi affairs lightly, especially on human rights matters" (par. 13). It is essential to remember that Saudi Arabia is among the top five source countries for international students in Canada (Statistics Canada, 2016; Remiorz, 2018). Thus, the Canadian media states that with the Saudi Arabian government's decision to withdraw its students out of Canadian schools, Canada's economy will be significantly affected (Remiorz, 218) as it will fail to generate revenues through Saudi students' sponsorship programs and labour contributions. This claim is inaccurate because the number of Saudi international students in Canada is quite small; therefore, their absence from Canadian campuses will certainly not have any severe impact 
on Canada's economy. It is also worth noting that there are currently over 1,000 medical trainees in Canada who are originally from Saudi Arabia. Weeks (2018) informs that the Canadian federal government and the Islamic Kingdom have recently reached a consensus to allow these trainees to stay in Canada until the end of September 2018, hence "buying hospitals an additional three weeks to figure out how to fill the gaps in the health-care system the departures will create" (par. 01).

Furthermore, the Islamic Kingdom's decision will have profound implications for all Saudi students who are either currently studying in Canada or are supposed to be here in the next couple of weeks. Indeed, Saudi Arabia's political move has left these students "scrambling with what to do with their lives" (Donovan, 2018, par. 06). Almost all of them are in shock right now because they do not know what their next steps will be (Rakobowchuk, 2018); more precisely, these students are unsure whether their earned course credits will be accepted if they decide to pursue their education from a different country. This is an unfair situation, especially for students who, despite having completed almost all the requirements for a Master's degree or a $\mathrm{PhD}$, will be travelling home without their degree (Rakobowchuk, 2018).

Over the past few weeks, Freeland (as cited in Remiorz, 2018) made a couple of statements to inform the public that Canada will welcome with open arms all Saudi students who have been accepted to pursue their education from a Canadian post-secondary institution. In fact, she posited that it would be ethically wrong if these students are prohibited from pursuing their educational endeavors from Canada (Chase, 2018) due to the on-going diplomatic tensions between the two countries. In short, as one can see, the effects of this diplomatic fight have put the future of current and incoming Saudi students to Canada at risk. Having said that, the following section critically 
examines some of the most prevalent knowledge gaps about international students in Canada that exist in the selected newspaper articles.

\subsection{Analysis \& Discussion}

One of the main weaknesses of the selected newspaper articles is that they mostly focus on a specific group of international students, excluding Bradshaw's (2018) article which highlights some of the strategies used by post-secondary institutions across Canada to help these individuals to integrate in their new society. For example, Bradshaw (2018) mentions that most institutions offer their foreign students "extra orientation beyond the general frosh week" (par. 05) to assist them in "getting a Canadian phone number and health insurance and learning where to eat on campus" (Bradshaw, 2018, par. 05), amongst other things. Although these strategies can be helpful to international students, one ought to remember that not all of their needs are the same; indeed, depending on their personality and the institution that they are attending, different international students have different needs to adjust to a new way of living and studying.

Unlike Bradshaw (2018), Habib's (2017a) article mainly focuses on the challenges encountered by male graduate international students upon their attempt to find employment. Surprisingly, the case of female undergraduate and graduate international students is not considered at all. It is critical to note that a job that a female graduate might accept if she misses out on her preferred profession is not always the same as her male counterparts; if Habib (2017a) had compared the struggles of both male and female graduate international students in finding a job, that would have strengthened her analysis. In fact, the case of female international students in Canada is overlooked in almost all of the selected newspaper articles. For instance, McDonald (2017) highlights psychological issues faced by international students in Canada, as well as the 
obstacles that they encounter and must surpass to be able to access certain services. The article is well-documented; however, it is focuses on male international students which does not provide a broad scope of analysis for the reader.

Another critical factor that has been neglected in some of these articles is that depending on their race, gender, religion, culture, and ethnicity, international students tend to react differently to their struggles, with each one of them having their own way of adjusting to life in Canada. To further explain this idea, let us refer to Attfield's (2017) article in which he identifies culture shock and the lack of on-campus settlement services as the main causes of international students' struggles with mental health issues and their subsequent suicidal attempts. While Attfield's (2017) analysis is accurate, the article fails to acknowledge the fact that the experiences of international students, along with their struggles with mental health issues, differ in terms of their race, gender, culture, and so forth. Attfield's (2017) analysis could have been stronger had he opted for an intersectional and comparative lens to investigate how different groups of international students cope with their mental health conditions.

Furthermore, it was previously mentioned that one of the main concerns of international students is that they must pay high tuition fees, coupled with other mandatory expenses. The impacts of this financial burden on international students are well explained in the selected articles. However, these articles fail to recognize that depending on the economic state of their home country and their families, not all international students are badly affected by high tuition fees. Indeed, international students from Europe from a wealthy family background are less likely to struggle to pay for their tuition fees and financially sustain themselves during their stay in Canada 
than African or Asian students who come from less financially privileged families, though the majority of them are rich.

Finally, it worth mentioning that unlike the academic literature, the Canadian media has addressed some unique themes, such as the impacts of faculty strikes on international students, more precisely on their study permit and their prospective plans for immigration (McKeen, 2017). McKeen's analysis of the impacts of faculty strikes on foreign students is good, but appears to be a bit too general. It would have been useful had he grounded his discussion on the demographical differences that exist among international students. Specifically, McKeen (2017) should have considered that different communities of students have different thought processes in the sense that not all of them cope with faculty strikes in the exact same way. In short, the Canadian media has so far done a good job of portraying the experiences and plight of international students in Canada. However, there is a lack of an intersectional approach that would have enabled the authors to put forth a detailed comparison of the struggles of these individuals based on their gender, nationality, culture, financial background, and so forth.

\subsection{Concluding Remarks}

As discussed throughout this chapter, the selected Canadian newspaper articles address critical issues encountered by both undergraduate and graduate international students in Canada. The major problems faced by these individuals are the high cost of education, mental health issues arising from a lack of support system and settlement services on- and off-campus, limited access to affordable health care coverage, and visa and study permit related issues. Although these issues have been discussed in depth in these articles, the selected readings contain some knowledge gaps that cannot be overlooked. To begin, it is important to note that most of the articles reviewed in 
this chapter primarily focus on the experiences and plight of male international students; very few of them consider the case of female students which is problematic. Apart from this, most of the articles focus on foreign students from South America, and Asia; other nationalities have been completely neglected. In addition, none of these media publications have addressed the struggles of graduate and undergraduate international students from European countries. In light of the discussion presented in this chapter, one can therefore accurately claim that the Canadian media often presents a decent picture of the struggles of international students in Canada, though some improvements can be made. 


\section{CHAPTER 5}

\section{Conclusion}

This literature review was initially meant to be shorter and be a part of a relatively larger comparative empirical study. Indeed, this study was supposed to compare and critically reflect upon the experiences and struggles of university and college international students in Ontario. Specifically, the aim was to recruit and interview a selected number of international students attending Ryerson University and Seneca College. Although this original project is undeniably interesting and ambitious, it could not be executed due to time constraints, more precisely due to the pending ethics' committee approval. Thus, my supervisor, Dr. Ghosh, and I mutually decided that it would be in my best interest if I decide not to conduct any form of primary research, but rather focus on secondary resources and write a thorough literature review that would not only highlight, but also compare the experiences and academic and non-academic challenges of these individuals as they have so far been reported in the academic literature and the Canadian media.

The purpose of this last chapter is to provide a summary of the main points discussed throughout this research paper. However, prior to summarizing the content of this literature review, it is critical to remind the reader the objectives of this study. As mentioned in the introductory chapter, the aim of this paper was to examine the experiences of international students in Canada, more precisely their academic and socio-cultural challenges by reviewing the extant academic literature and the Canadian media. Another purpose of this paper was to identify some of the most prevalent knowledge gaps about international students in Canada in these two information sources.

As discussed in the third chapter of this paper, the number of international students in Canada has been steadily increasing since the last 20 years and this is mainly due to various strategies used by the Canadian federal government to attract these individuals. Unfortunately, despite 
representing a precious human capital for Canada's economy and enriching the socio-cultural climate of this country, these international students are persistently confronted with numerous challenges, including language and socio-cultural barriers, racial discrimination, and microaggression, amongst other issues. While there are some settlement services and support available for these individuals, these are either unknown to them, or are not comprehensive enough to fulfill their integration needs.

Despite the experiences of international students in Canada being well portrayed and discussed in the academic literature and the Canadian media, a number of knowledge gaps about these individuals exist in these two information sources. To begin, this paper demonstrated that the experiences and struggles of specific groups of international students in Canada, notably female undergraduate and graduate students and undergraduate students as a whole, are usually overlooked. Similarly, it is now evident that there is a significant lack of comparative empirical studies on international students in Canada, mainly in Ontario, to enable us to properly assess and accurately compare the experiences of these individuals based on the geographical setting and the type of the institution that they are attending, as well as on a wide range of other factors, including race, gender, and cultural, ethnic, and financial background, and so forth.

Within this framework of discussion, it is critical to mention that although the existing academic literature fairly excels at addressing the challenges encountered by foreign students onand off-campus, it is not sufficient for the reader to thoroughly investigate the nature of these issues. Thus, there is a pressing need for additional research to be conducted, so that appropriate services can be fostered by the Canadian post-secondary sector and the federal government to enable international students to simultaneously cope with their on- and off-campus struggles. 
Another major gap in the extant literature is that it does not adequately address the struggles of international students who are either from Europe, the Middle-East, or Africa, rather, most studies predominantly focus on Chinese and Indian students. Therefore, more research needs to be conducted in the coming years to enable both the researcher and the public to become more familiar with the experiences of foreign students from diverse backgrounds.

A major limitation of this study is that it only looked at the academic literature and two Canadian newspapers to discuss the experiences of international students in Canada. To gain a thorough insight into the struggles of these students, it would be useful to review articles from other Canadian newspapers. In addition, considering that China and India are among the top source countries for international students in Canada (Statistics Canada, 2016), it would be interesting to review the Indian and Chinese media to see how the experiences of these students are portrayed in these specific information sources. To conclude, a major lesson that one can take away from this literature review is that the quality of the existing academic and Canadian media literature on the topic of international students in Canada is good, but not strong enough to enable us to understand how the experiences and integration needs of these individuals differ on a macro- and micro-level. 


\section{References}

Arat-Koç, S. (1999). “Neo-Liberalism, State Restructuring and Immigration: Changes in Canadian Policies in the 1990s", Journal of Canadian Studies, 34(2), pp. 31-56. Retrieved from: https://search-proquest-com.ezproxy.lib.ryerson.ca/docview/203523986?pqorigsite $=$ summon.

Attfield, P. (2017). "You Are Not Alone: University Services for Students Who Are Struggling", The Globe and Mail. Retrieved from: https://www.theglobeandmail.com/report-onbusiness/you-are-not-alone-university-services-for-students-who-arestruggling/article36594429/.

Beck, K., Zhang, Z. (2014). “I came, but I'm lost: Learning Stories of Three Chinese International Student in Canada", Canadian and International Education, 43(02), article 06, pp. 01-14. Retrieved from: https://ir.lib.uwo.ca/cgi/viewcontent.cgi?referer=https://www.google.ca/\&httpsredir=1\&art $\underline{\text { icle}=1297 \& \text { context }=\text { cie-eci. }}$.

Belkhodja, C., Esses, V. (2013). “Improving the Assessment of International Students' Contribution to Canadian Society", pp. 01-26. Retrieved from: http://p2pcanada.ca/wpcontent/uploads/2014/02/International-Students-Contribution-to-Canadian-Society.pdf.

Bradshaw, J. (2018). "How Canadian Schools Are Helping International Students Fit In", The Globe and Mail. Retrieved from: https://www.theglobeandmail.com/news/national/howcanadian-schools-are-helping-international-students-fit-in/article13993975/. 
Brown, L. (2014). “International Students or 'Cash Cows'?”, The Star. Retrieved from: https://www.thestar.com/yourtoronto/education/2014/09/11/international_students_or_cash cows.html.

Calder, M.J., et al. (2016). "International Students Attending Canadian Universities: Their Experiences with Housing, Finances, and Other Issues", Canadian Journal of Higher Education, 46(02), pp. 92-110. Retrieved from: https://repository.up.ac.za/bitstream/handle/2263/61599/Calder International 2016.pdf?se quence $=1$.

Cameron, J.D. (2006). "International Student Integration into the Canadian University: A PostWorld War Two Historical Case Study", History of Intellectual Culture, 06(01), pp. 01-18. Retrieved from: https://www.ucalgary.ca/hic/files/hic/cameron-on-student-integration.pdf.

Chakma, A. (2010). "Internationalizing Canada's Student Experience", The Globe and Mail. Retrieved from: https://www.theglobeandmail.com/opinion/internationalizing-canadasstudent-experience/article4324212/.

Chase, S. (2018). "Saudi Arabia Withdrawing Students From Canadian School, Suspending Flights", The Globe and Mail. Retrieved from: https://www.theglobeandmail.com/canada/article-saudi-arabia-to-withdraw-all-saudistudents-studying-at-canadian/.

Cooper, L. (2017). “Attracting International Talent”, RBC Economics, pp. 01-03. Retrieved from: http://www.rbc.com/economics/economic-reports/pdf/otherreports/International\%20students-May2017.pdf. 
Donovan, V. (2018). "Saudi Arabia Orders its Foreign Students Out of Canadian Schools", The Star. Retrieved from: https://www.thestar.com/news/canada/2018/08/06/saudi-arabiaorders-its-foreign-students-out-of-canadian-schools.html.

Fiorito, J. (2008). “The Foreign Student Learned Hard Lesson in Toronto", The Star. Retrieved from: https://www.thestar.com/opinion/columnists/2008/03/21/foreign student learned hard les son in toronto.html.

Gates-Gasse, E. (2012) “International Students as Immigrants.” Immigration and Settlement: Challenges, Experiences, and Opportunities. Ed: Harald Bauder. Toronto: Canadian Scholars’ Press Inc., pp. 271-296.

Habib, M. (2017a). "New to Canada, Struggling to Find Work", The Globe and Mail. Retrieved from: https://www.theglobeandmail.com/news/national/education/new-to-canadastruggling-to-find-work/article36660656/.

Habib, M. (2017b). "What I Wish I Knew Before I Started University”, The Globe and Mail. Retrieved from: https://www.theglobeandmail.com/news/national/education/canadianuniversity-report/what-i-wish-i-knew-before-i-started-university/article36637610/.

Hawthorne, L. (2012). “Designer Immigrants? International Students and Two-Step Migration”, Internationalization Abroad, pp. 417-435. Melbourne: University of Melbourne Library. Retrieved from: https://www.researchgate.net/publication/259198256 Designer Immi grants International $\underline{\text { Students and Two-Step Migration. }}$ 
Hinkson, K. (2013). “Canadian Universities Assisting International Students Caught in Visa Backlog", The Star. Retrieved from: https://www.thestar.com/news/canada/2013/08/16/canadian_universities_assisting_internat ional_students_caught_in_visa_backlog.html.

Houshmand, S., et al. (2014). "Excluded and Avoided: Racial Microaggressions Targeting Asian International Students in Canada", Cultural Diversity and Ethnic Minority Psychology, 20(03), pp. 377-388. Retrieved from: https://pdfs.semanticscholar.org/9415/398532c6764b7e3e38a443c64b5f6dcd5eed.pdf.

Keung, N. (2015). “Toronto Universities Team Up on Foreign Student Peer Group”, The Star. Retrieved from: https://www.thestar.com/news/immigration/2015/03/18/torontouniversities-team-up-on-foreign-student-peer-group.html.

Loriggio, P. (2017). “International Students Face Uncertainty Over Ontario Colleges Strike”, The Star. Retrieve from: https://www.thestar.com/yourtoronto/education/2017/10/22/international-students-faceuncertainty-over-ontario-colleges-strike.html.

McDonald, G. (2017). "For Some Students, The Transition to University Can Be Hard on Mental Health", The Globe and Mail. Retrieved from: https://www.theglobeandmail.com/life/parenting/back-to-school/the-transition-touniversity-can-be-hard-on-mental-health/article36003286/. 
McKeen, A. (2017). “Options Sparse for International Students Impacted by College Strike”, The Star. Retrieved from: https://www.thestar.com/news/gta/2017/11/24/options-sparse-forinternational-students-impacted-by-ontario-college-strike.html.

Minister of Public Works and Government Services Canada. (2011). "Study in Canada: Visas, Work, and Immigration for International Students", Citizenship and Immigration Canada, pp. 02-10. Retrieved from: http://www.cic.gc.ca/english/pdf/pub/study.pdf.

Naidoo, D. (2012). “Chapter 5: Findings and Discussion - Academic (Dis)location/Social (Dis)location”, The Experiences of In/Exclusion and Marginalization of International Students at a Private Higher Education Institution, MA Thesis Submitted to the University of Witwatersrand,pp. 90-101. Retrieved from: http://wiredspace.wits.ac.za/bitstream/handle/10539/18218/FINAL\%20SUBMISSION\%20 (WITH\%20CORRECTIONS)-\%2027\%20May.pdf?sequence=2.

Ngabo, G. (2018). “I, The Skinny Kid from Rural Rwanda Who Dared to Dream, Am Now a Canadian", The Star. Retrieved from: https://www.thestar.com/news/gta/2018/07/13/imcanadian-i-just-got-my-citizenship-im-so-happy.html.

Pang, W. (2017). "Peace of Mind: Universities See Spike in Students Seeking Mental-Health Help", The Globe and Mail. Retrieved from: https://www.theglobeandmail.com/news/national/education/peace-of-mind-universitiessee-spike-in-students-seeking-mental-health-help/article36637574/. 
Poteet, M., Gomez, B. (2015). “It’s Both Ways: How International Students Negotiate Belonging in Local and Global Contexts”, Journal of New Brunswick Studies, 06(1), pp. 83-102. Retrieved from: https://journals.lib.unb.ca/index.php/JNBS/article/viewFile/23061/26777.

Prairie Research Associates. (2009). Canada First: The 2009 Survey of International Students. Ottawa: Canadian Bureau for International Education., pp. 01-66. Retrieved from: https://cbie.ca/wp-content/uploads/2016/06/Canada-First-20091.pdf.

Rae Cox, C. (2014). "International Students in Canada: Policies and Practices for Social Inclusion", Major Research Paper, pp. 01-123. Retrieved from: http://digital.library.ryerson.ca/islandora/object/RULA\%3A3281.

Rakobowchuk, P. (2018). "Saudi Student Given Four Weeks to Leave Canada, Even If Studies Not Completed", The Star. Retrieved from: https://www.thestar.com/news/canada/2018/08/07/saudi-students-given-four-weeks-toleave-canada-even-if-studies-not-completed.html.

Roach, E., (2011). "Service Needs and Gaps for International Students Transitioning to Permanent Residency in a 'Two-Step' Immigration Process: A Toronto-Based Study”, Major Research Paper, pp. 01-66. Retrieved from: http://digital.library.ryerson.ca/islandora/object/RULA\%3A6151. 
She, Q., Wotherspoon, T. (2013). "International Student Mobility and Highly Skilled Migration: A Comparative Study of Canada, the United States, and the United Kingdom”, SpringerPlus, 02(01), issue 32, pp. 01-14. Retrieved from: https://link-springercom.ezproxy.lib.ryerson.ca/content/pdf/10.1186\%2F2193-1801-2-132.pdf.

Statistics Canada. (2016). "International Students in Canadian Universities, 2004/2005 to 2013/2014”, pp. 02-12. Retrieved from: http://www.statcan.gc.ca/pub/81-599-x/81-599x2016011-eng.pdf.

Thomson, C., Esses, V.M. (2016). "Helping the Transition: Mentorship to Support International Students in Canada", Journal of International Students, 06(04), pp. 873-886. Retrieved from: https://search-proquestcom.ezproxy.lib.ryerson.ca/docview/1861791247/fulltextPDF/F5A4274F713E4352PQ/1?a c countid=13631.

UIS. (n.d.). "Welcome to UIS. Stat.” Retrieved from: http://data.uis.unesco.org/\#.

UIS. (2018). “Education.” Retrieved from: http://data.uis.unesco.org/Index.aspx?DataSetCode=EDULIT DS\&popupcustomise=true\& lang=en\#.

UNESCO. (2018). "Methodology.” Retrieved from: http://uis.unesco.org/en/methodology. 
Wang, Y. (2016). “The Adjustment Journey of International Students in Tertiary Education”, MEd MRP Submitted to the University of Victoria, pp. 01-51. Retrieved from: https://dspace.library.uvic.ca/bitstream/handle/1828/7333/Wang_Yue_MEd_2016.pdf?seq uence $=4$ \&isAllowed $=y$.

Weeks, C. (2018). “More Than 1,100 Saudi Medical Residents Get Extended Deadline to Leave Canada", The Globe and Mail. Retrieved from: https://www.theglobeandmail.com/canada/article-over-1100-saudi-medical-residents-getextended-deadline-to-leave/.

Wu, H-P., et al. (2015). “International Students' Challenge and Adjustment to College”, Education Research International, pp. 01-09. Retrieved from https://www.hindawi.com/journals/edri/2015/202753/.

Yalnizyan, A., Grisdale, C. (2016). "International Students Are an Asset We Need to Cultivate", The Star. Retrieved from: https://www.thestar.com/opinion/commentary/2016/09/13/international-students-are-anasset-we-need-to-cultivate.html.

Zhou, G., Zhang, Z. (2014). "A Study of the First Year International Students at a Canadian University: Challenges and Experiences with Social Integration”, Canadian and International Education, 43(02), article 07, pp. 01-17. Retrieved from: https://ir.lib.uwo.ca/cgi/viewcontent.cgi? article=1288\&context=cie-eci. 